\title{
A Randomized, Double Blinded, Clinical Trial to Assess the Efficacy and Cost Effectiveness of Omeprazole Compared to Rabeprazole in the Maintenance Therapy of Patients With Gastroesophageal Reflux Disease
}

\author{
Jung Ho Park, ${ }^{1}$ Hyojin Park, ${ }^{2 *}$ Dong Ho Lee ${ }^{3}$ and In Kyung Sung ${ }^{4}$ \\ ${ }^{1}$ Department of Internal Medicine, Kangbuk Samsung Hospital, Sungkyunkwan University College of Medicine, Seoul, Korea; ${ }^{2}$ Department of \\ Internal Medicine, Yonsei University College of Medicine, Seoul, Korea; ${ }^{3}$ Department of Internal Medicine, Seoul University College of \\ Medicine, Seoul, Korea; and ${ }^{4}$ Department of Internal Medicine, Kunkook University College of Medicine, Seoul, Korea
}

\section{Background/Aims}

The aim of this study was to evaluate the efficacy and cost efficiency of omeprazole $10 \mathrm{mg}$ and rabeprazole $10 \mathrm{mg}$ once daily for 24 weeks in the maintenance therapy.

\section{Methods}

This was a randomized, open-label study enrolling 279 patients with erosive esophagitis A or B (Los Angeles classification) and typical gastroesophageal reflux disease symptoms. Patients who showed complete endoscopic and symptomatic healing after 8 weeks of proton pump inhibitor treatment were randomly allocated to maintenance treatment with omeprazole $10 \mathrm{mg}$ once daily or rabeprazole $10 \mathrm{mg}$ once daily for 42 weeks. The primary efficacy endpoint was the proportion of patients with symptomatic remission at 42 weeks.

Results

At the end of 42 weeks of maintenance therapy, $96.4 \%$ of omeprazole and $95.1 \%$ of rabeprazole treated patients remained symptom free $(P>0.05)$. Two drugs were also comparable with regard to the severity and frequency of reflux symptoms during the maintenance phase $(P>0.05)$. By the cost-minimization analysis, the mean total costs per patient for remaining symptom-free for 6 months were 241,775 won for omeprazole and 287,115 won for rabeprazole, respectively.

\section{Conclusions}

Omeprazole $10 \mathrm{mg}$ appeared to have similar efficacy in maintaining symptomatic remission as rabeprazole $10 \mathrm{mg}$, but was superior to rabeprazole $10 \mathrm{mg}$ in terms of cost efficiency in the maintenance therapy of gastroesophageal reflux disease symptoms.

(J Neurogastroenterol Motil 2013;19:219-226)

\section{Key Words}

Cost-benefit analysis; Gastroesophageal reflux; Maintenance

Received: November 21, 2012 Revised: January 7, 2013 Accepted: January 7, 2013

(c) This is an Open Access article distributed under the terms of the Creative Commons Attribution Non-Commercial License (http://creativecommons. org/licenses/by-nc/3.0) which permits unrestricted non-commercial use, distribution, and reproduction in any medium, provided the original work is properly cited.

*Correspondence: Hyojin Park, MD, PhD

Department of Internal Medicine, Kangnam Severance Hospital, Yonsei University College of Medicine, 211, Eonju-ro, Gangnam-gu, Seoul 135-720, Korea

Tel: +82-2-3497-3310, Fax: +82-2-3463-3882, E-mail: HJPARK21@yuhs.ac

Financial support: This study was funded by SK chemicals.

Conflicts of interest: None.

Author contributions: Jung Ho Park, Hyojin Park, Dong Ho Lee and In Kyung Sung: planning, conducting and collecting data. Jung Ho Park: writing the paper. 
of continuous omeprazole therapy.

\section{Introduction}

Gastroesophageal reflux disease (GERD) is a major public health problem in Korea. GERD affects approximately 3.4-3.8\% of the Korean population ${ }^{1,2}$ and its incidence is on the increase. Generally, treatment of GERD begins with suppression of acid secretion by proton pump inhibitors (PPIs). PPI therapy relieved symptoms and healed the esophagitis in more than $80 \%$ of patients within 8 weeks of treatment, ${ }^{3}$ and it was better than placebo and histamine 2 receptor antagonist therapy as the treatment for esophagitis at 4-8 weeks. ${ }^{4}$ However, due to the recurring nature of GERD, most patients require additional long-term maintenance therapy.

Management options for the long-term management of GERD are either daily therapy or on-demand therapy of PPI. On-demand therapy is an adequate option for patients with non-erosive reflux disease (NERD) and uninvestigated GERD without alarm features. ${ }^{5-8}$ In contrast, continuous treatment is effective in the maintenance of healing in patients with esophagitis. ${ }^{9}$ And also, continuous treatment was preferred over on-demand therapy in patients with esophagitis, in the elderly ${ }^{10}$ and in patients with Barrett's esophagus ${ }^{11}$ since on-demand treatment is less cost-saving in patients with esophagitis and symptomatic relapses occur frequently in severe grades.

Continuous PPI therapy for reflux esophagitis is associated with a large economic burden. Therefore, it is important to use the most cost effective PPIs at the adequate dose. Omeprazole is the oldest PPI approved for clinical use in the treatment and prevention of reflux esophagitis. ${ }^{12,13}$ Although new PPIs have been developed since, omeprazole $20 \mathrm{mg}$ is still as effective as the new PPIs including rabeprazole $20 \mathrm{mg}$, lansoprazole $30 \mathrm{mg}$ and pantoprazole $40 \mathrm{mg}$ in the acute treatment of reflux esophagitis and prevention of the relapse of esophagitis. ${ }^{14-17}$

In terms of half dose omeprazole, maintenance treatment with omeprazole $10 \mathrm{mg}$ daily keeps about $60 \%$ of patients with erosive esophagitis free of relapse ${ }^{18}$ and half dose omeprazole was recommended in the prevention of relapse of esophagitis. ${ }^{19}$ However, little information is available about its effectiveness compared with other newer half dose PPI drugs in continuous PPI therapy for reflux esophagitis.

Therefore, in this study, we tried to determine the efficacy and cost effectiveness of maintenance therapy with omeprazole $10 \mathrm{mg}$ compared with rabeprazole $10 \mathrm{mg}$ in patients with reflux esophagitis who experienced symptom resolution after an 8 week course

\section{Materials and Methods}

\section{Patients}

Subjects with typical GERD symptoms such as heartburn, regurgitation or epigastric pain for 2 days or more during the last 7 days were enrolled in the healing phase of the trial if they met the following eligibility criteria: were 18 to 75 years of age with a history of reflux symptoms for 6 months or longer, and had endoscopically proven erosive esophagitis (Grade A or B using Los Angeles [LA] classification of esophagitis). All participants either underwent esophagogastroduodenoscopy (EGD) at baseline, or had undergone EGD within 2 weeks prior to enrollment. Exclusion criteria were as follows: endoscopically proven Grade $\mathrm{C}$ or $\mathrm{D}$ esophagitis; presence of another organic lesion on endoscopy such as peptic ulcer or Barrett's esophagus; past history of gastric or esophageal surgery; signs of gastrointestinal bleeding at the time of EGD; chronic alcoholism ( $>40 \mathrm{~g}$ alcohol/day); heavy smoking ( $>2$ packs/day); pregnancy or lactation; presence of abnormal liver function test $(>2 \times$ normal AST and ALT); known hypersensitivity to any component of omeprazole or rabeprazole; and concomitant diseases that might affect the results such as epilepsy or manic-depressive disorder. Patients were also excluded if they had received PPI or histamine 2 blocker therapy within 15 days before the screening date, or had received other medications that might affect the interpretation of the treatment outcome (quinidine, high dose corticosteroid, nonsteroidal anti-inflammatory, wafarin, anticholinergic, prostaglandin analogue or salicylate [except low dose aspirin]).

\section{Study Design}

This was a multi-center, randomized, double blinded, noninferiority study consisting of a healing phase and a maintenance phase (Fig. 1). All patients received open-label oral omeprazole $20 \mathrm{mg}$ once daily for 8 weeks. Repeat EGD was performed at the end of 8 weeks. This study was undertaken according to the principles of the Declaration of Helsinki and local ethics committee approval was obtained before the start of the study. Patients whose esophagitis was healed and were asymptomatic started maintenance treatment with omeprazole $10 \mathrm{mg}$ q.d. or rabeprazole $10 \mathrm{mg}$ q.d. for 24 weeks. 'Healing' was defined as no macroscopic mucosal breaks based on the LA classification, and 'asymptomatic' was defined as having complete resolution of reflux 


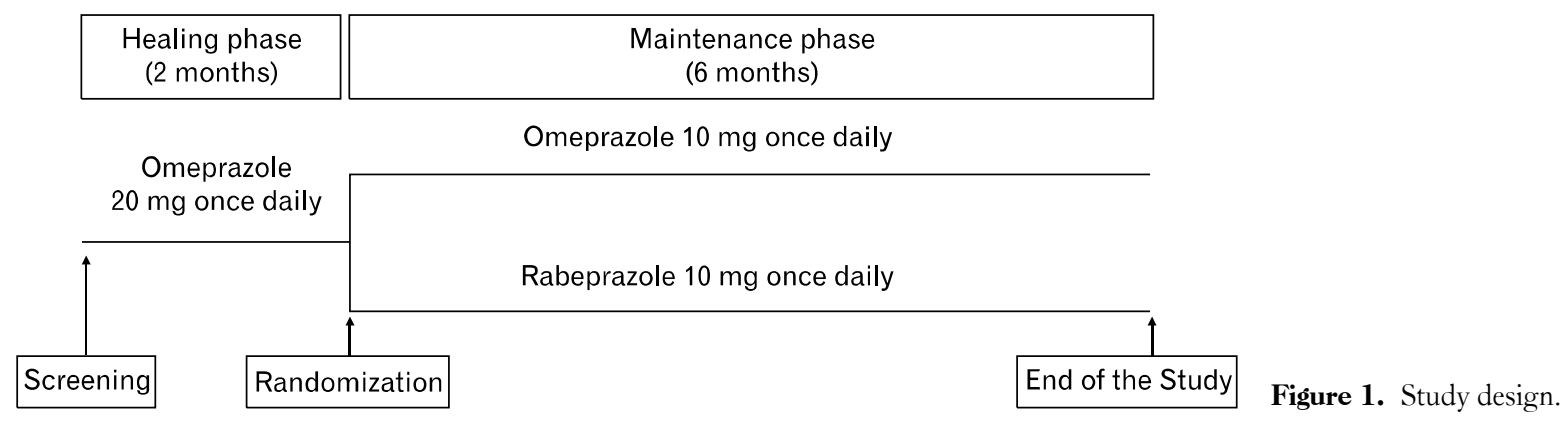

symptoms (defined as no reflux symptoms during the last 7 days prior to the visit) or relief of reflux symptoms (defined as no more than 1 day with a mild episode of reflux symptom during the last 7 days prior to the visit). Those who were not healed or were symptomatic at the end of the healing phase were not considered for maintenance therapy.

Maintenance treatment continued for 24 weeks. Patients were instructed to visit the outpatient clinic every month to receive drugs and report their symptoms and fill out the quality of life (QOL) questionnaire, the Korean version of EuroQol 5 dimensions (KEQ-5D). The occurrence and severity of GERD symptoms during the previous week were recorded using a questionnaire. Symptomatic relapse during the maintenance phase was defined as no more than 1 day of mild reflux symptoms (heartburn, acid regurgitation or epigastric pain) or moderate to severe reflux symptoms during the 1 week prior to visit. Severity of GERD symptoms was assessed as $0=$ none; $1=$ mild (present but causing little or no discomfort and can be ignored when not thought about); 2 = moderate (causes discomfort and some interference with daily routine); and $3=$ severe (disabling and interferes considerably with the daily routine). KEQ-5D consists of 5 dimensions: mobility, self-care, usual activities, pain/ discomfort and anxiety/depression. The reason why KEQ-5D was used here is that it was recently validated for QOL in Koreans. ${ }^{20}$ It is mainly used for calculating quality-adjusted life years in pharmacoeconomic studies. ${ }^{21}$

Laboratory tests, including complete blood count, clinical chemistry, urinalysis, and pregnancy test (for female subjects with reproductive potential) were performed at the screening and at the end of the maintenance phase. In addition to the screening endoscopy, patients underwent endoscopy at the end of the healing phase and at the end of the maintenance phase. Assessments of adverse events were performed during all visits and were graded in terms of severity and relationship to the study drug.

\section{Efficacy and Cost Effectiveness Assessment}

The primary aim of the study was to evaluate the resolution rates of GERD symptoms after 6 months of maintenance treatment with omeprazole $10 \mathrm{mg}$ q.d. and rabeprazole $10 \mathrm{mg}$ q.d., and to compare them. Secondary efficacy variables included changes in the severity and frequency of symptoms, recurrence rates of esophagitis at the end of maintenance phase, and improvement in the QOL. The main safety outcome was the occurrence of adverse events and cost effectiveness during the maintenance phase. For the evaluation of cost effectiveness in this study, a cost minimization study was the appropriate form of economic analysis, since utility gains were comparable for omeprazole $10 \mathrm{mg}$ and rabeprazole $10 \mathrm{mg}$.

Costs were classified into direct and indirect costs. Direct costs consisted of payments for outpatient services and diagnostic tests such as endoscopy and medications. Indirect costs referred to transportation. Data on the direct and indirect costs were calculated for each patient during 6 months after randomization, and an average cost for each item was estimated based on information from the National Health Insurance Corporation, domestic and foreign pharmacoeconomic journals and Statistics Korea. In addition, decision tree sensitivity analyses were performed to judge the robustness of the conclusions made with the various cost assumptions. A decision tree model for 1 year was developed to simulate possible treatment modalities for 6 months after maintenance treatment of GERD (Fig. 2). Recurrence rates and proportion of actual treatment modality assignment were based on the study conducted in Korea. ${ }^{23}$

\section{Statistical Methods}

Efficacy of omeprazole was assessed as not inferior to that of rabeprazole in GERD patients. The predefined non-inferiority margin was an absolute difference of $20 \%$ in the primary endpoint between two groups. To test for non-inferiority with a back- 
ground remission rate of $62-82 \%^{13,18,19}$ at 6 months by half dose omeprazole maintenance treatment with absolute non-inferiority margin of $20 \%$, a total sample size of 92 patients was calculated for $80 \%$ power at a $5 \%$ significance level. Analysis was performed for the intention-to-treat (ITT) population, which included all patients who had received at least one dose of the study medication. The primary efficacy analysis was a comparison of the percentage of patients who remained healed (resolution rates) between the 2 maintenance treatment groups, using a Chi-square test or Fisher's exact test. Secondary endpoints were also analyzed on the ITT population. Difference of symptom severity (expressed on a 4-point scale), frequency and recurrence rates of reflux esophagitis between the 2 groups were analyzed with a Chisquare test or Fisher's exact test.

\section{Results}

\section{Patient Disposition}

A total of 239 patients received acute treatment. At the end of the acute treatment phase, only 165 patients experienced complete resolution of reflux symptoms and erosive esophagitis and qualified for randomization in the maintenance treatment phase. All 165 patients who entered the maintenance treatment were included in the ITT analyses. Of these patients, 83 were randomly assigned to receive omeprazole $10 \mathrm{mg}$ once daily and 82 assigned to receive rabeprazole $10 \mathrm{mg}$ once daily for 6 months (Fig. 3). Within the ITT population, there were no significant differences

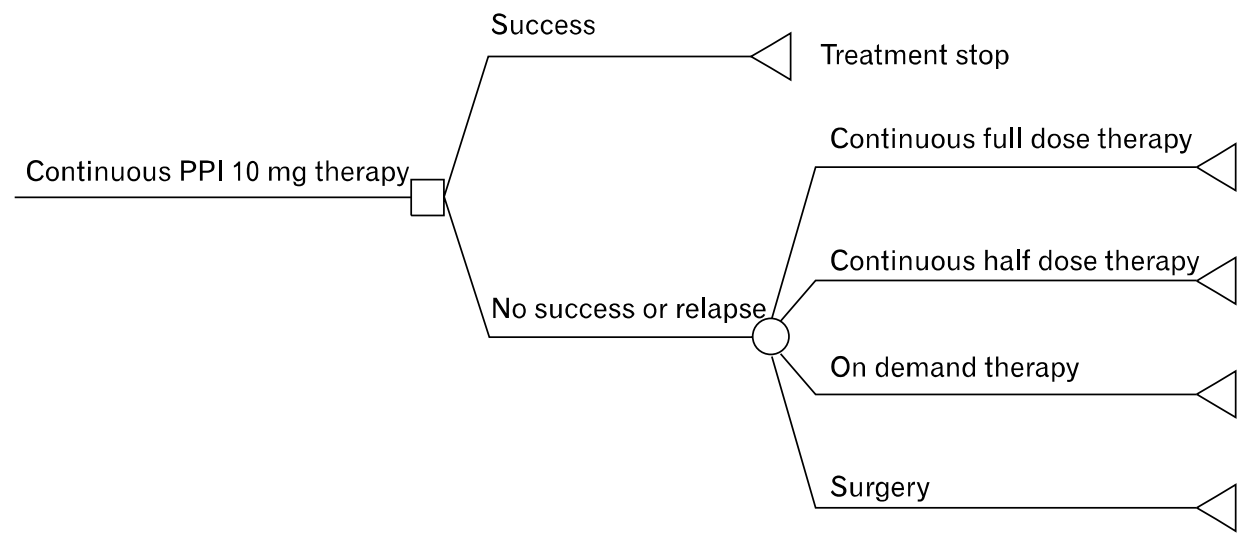

Figure 2. Decision tree for management plans after 6 months maintenance therapy for gastroesophageal reflux disease. PPI, proton pump inhibitor.

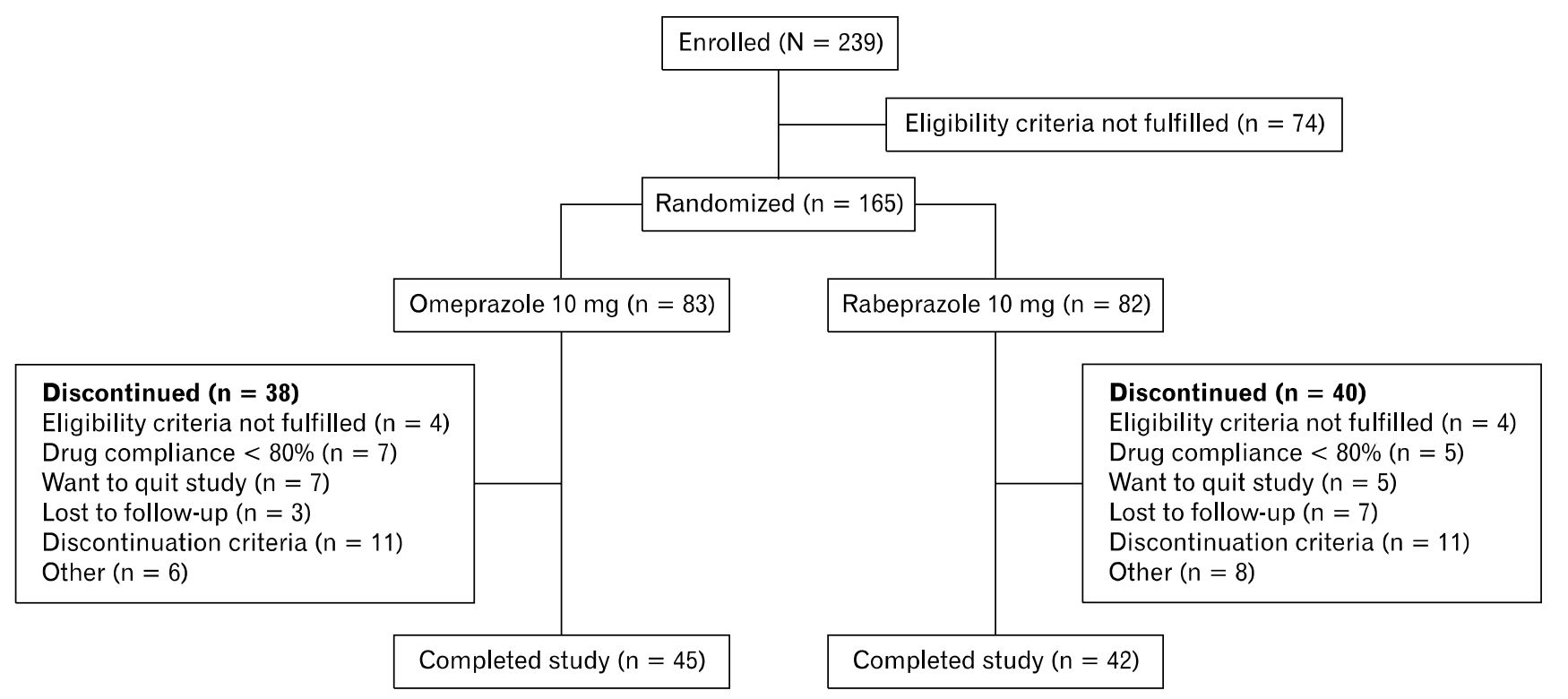

Figure 3. Flowchart of patient management in the study. 
between the 2 treatment groups in demographic variables, past medical histories and medications (Table 1). A total of 87 patients completed the trial through to the end of the 6-month maintenance treatment ( 45 who received omeprazole and 42 who received rabeprazole).

\section{Primary Efficacy Endpoint}

For the ITT patients, symptom resolution rates observed at week 24 were $96.4 \%$ for the omeprazole $10 \mathrm{mg}$ group and $95.1 \%$ for the rabeprazole $10 \mathrm{mg}$ group. Symptom resolution rates for the two treatment groups did not differ significantly for any visit week $(P>0.05)$. Results were similar for the per protocol population.

\section{Secondary Efficacy Endpoint}

\section{Symptom frequency and severity}

Table 2 summarizes the symptom frequency and severity at the last visit for both treatment groups. There were no significant differences between the treatment groups.

\section{Recurrence rate of reflux esophagitis (endoscopy)}

Four $(6.7 \%)$ patients in the omeprazole group had a relapse

Table 1. Demographic Characteristics

\begin{tabular}{lcc}
\hline \multicolumn{1}{c}{ Characteristic } & $\begin{array}{c}\text { Omeprazole } \\
(\mathrm{n}=83)\end{array}$ & $\begin{array}{c}\text { Rabeprazole } \\
(\mathrm{n}=82)\end{array}$ \\
\hline Age (mean $\pm \mathrm{SD}, \mathrm{yr})$ & $47.8 \pm 12.8$ & $47.2 \pm 12.9$ \\
Gender $(\mathrm{M} / \mathrm{F})$ & $57 / 26$ & $59 / 23$ \\
Body weight $($ mean $\pm \mathrm{SD}, \mathrm{kg})$ & $68.2 \pm 11.7$ & $66.1 \pm 10.1$ \\
Users of Alcohol (n [\%]) & $47(56.6)$ & $48(58.5)$ \\
Smokers (n [\%]) & $24(28.9)$ & $22(26.8)$ \\
KEQ-5D utility (mean $\pm \mathrm{SD})$ & $0.94 \pm 0.12$ & $0.93 \pm 0.10$ \\
\hline
\end{tabular}

KEQ-5D, Korean version of EuroQol 5 dimensions. and $4(6.9 \%)$ patients in the rabeprazole group relapsed. No significant difference existed between the treatment groups $(P=$ 1.000). Severity of recurred erosive esophagitis was also not significantly different between the 2 groups (LA-A: 3 patients, LA-minimal change: 1 patient in the omeprazole group; LA-A: 2 patients, LA-minimal change: 2 patients in the rabeprazole group).

\section{KEQ-5D}

At baseline, no significant difference in the mean utility scores existed between patients in the omeprazole and rabeprazole groups. After 24 weeks, the mean utility score for patients in the omeprazole group was $0.96 \pm 0.10$ compared with $0.96 \pm$ 0.08 in the rabeprazole group. Therefore, there was no statistical significant difference in improvement of QOL between the two groups after treatment.

\section{Safety Evaluation}

During the maintenance phase, a total of 143 adverse events were reported by $68(41.21 \%)$ patients during the 24 weeks of treatment. Thirty-three of the $83(39.75 \%)$ patients in the omeprazole group reported 72 events and 35 of the 82 (42.68\%) patients in the rabeprazole group experienced 71 events. There was no significant difference between the treatments for any of the events considered to be possibly or probably related to the treatment. The same was true for the incidence of adverse events when categorized by body system.

\section{Cost Minimization Analysis}

There was no significant difference in utility weight between 2 treatments before and after maintenance treatments. Therefore, a cost minimization approach was considered to appropriate. The treatment that was associated with a lower cost of medicine was

Table 2. Frequency and Severity of Symptom Recurrence at the End of Maintenance Treatment

\begin{tabular}{|c|c|c|c|c|c|c|c|c|c|}
\hline & \multirow{2}{*}{ Severity } & \multirow{2}{*}{$\begin{array}{c}\text { Omeprazole } \\
\text { n }(\%)\end{array}$} & \multirow{2}{*}{$\begin{array}{c}\text { Rabeprazole } \\
\text { n (\%) }\end{array}$} & \multirow{2}{*}{$P$-value } & \multicolumn{2}{|c|}{ Omeprazole } & \multicolumn{2}{|c|}{ Rabeprazole } & \multirow{2}{*}{$P$-value } \\
\hline & & & & & Frequent rate $(\%)$ & $95 \% \mathrm{CI}$ & Frequent rate $(\%)$ & $95 \% \mathrm{CI}$ & \\
\hline \multirow[t]{3}{*}{ Heart burn } & No & 78 (93.98) & $75(91.46)$ & 0.713 & 17.78 & $(6.61-28.95)$ & 23.81 & $(10.93-36.69)$ & 0.488 \\
\hline & Mild & $4(4.82)$ & $5(6.10)$ & & & & & & \\
\hline & Moderate & $1(1.2)$ & $2(2.44)$ & & & & & & \\
\hline \multirow[t]{2}{*}{ Regurgitation } & No & 78 (93.98) & $80(97.56)$ & 0.443 & 2.22 & $(0.00-6.53)$ & 4.76 & $(0.00-11.20)$ & 0.608 \\
\hline & Moderate & $0(0.00)$ & $0(0.00)$ & & & & & & \\
\hline \multirow[t]{3}{*}{ Epigastric pain } & No & 78 (93.98) & $79(96.34)$ & 0.443 & 8.89 & $(0.57-17.20)$ & 11.90 & $(2.11-21.70)$ & 0.733 \\
\hline & Mild & $5(6.02)$ & $2(2.44)$ & & & & & & \\
\hline & Moderate & $0(0.00)$ & $1(1.22)$ & & & & & & \\
\hline
\end{tabular}


Table 3. Comparison of Direct, Indirect and Total Resource Costs Between the 2 Proton Pump Inhibitor Drugs

\begin{tabular}{rrrrrrr}
\hline $\begin{array}{c}\text { Outpa- } \\
\text { tient cost }\end{array}$ & $\begin{array}{c}\text { Drug } \\
\text { cost }\end{array}$ & $\begin{array}{c}\text { Drug } \\
\text { dispensing }\end{array}$ & $\begin{array}{c}\text { Cost of } \\
\text { testing }\end{array}$ & $\begin{array}{c}\text { Travel } \\
\text { cost }\end{array}$ & $\begin{array}{c}\text { Total cost } \\
\text { (won/6 mo) }\end{array}$ \\
\hline Omeprazole 26,505 & 84,960 & 25,212 & 47,431 & 57,648 & 241,755 \\
Rabeprazole & 26,505 & 130,320 & 25,212 & 47,431 & 57,648 & 287,115 \\
\hline
\end{tabular}

(As of 24 November 2011, 1 USD = 1,176.33 won)

omeprazole $10 \mathrm{mg}$ of 84,940 won at 6 months compared with 130,320 won (as of 24 November 2011, 1 USD $=1,176.33$ won) for rabeprazole $10 \mathrm{mg}$ at 6 months. The same difference was obtained with total costs, and PPI drug costs accounted for $46.1 \%$ of the total direct costs (Table 3 ). Omeprazole was the less costly option for the maintenance treatment of GERD compared with rabeprazole.

\section{Sensitivity Analysis}

Figure 2 depicts a decision tree to illustrate the possible management modalities after 6 months maintenance treatment of GERD. Baselines of relevant treatment plans are shown in Table 4 with recurrence rates of GERD after 6 months maintenance treatment and the proportion of subsequent treatment modalities. The total annual expense of treatment with omeprazole is 249,540 won and treatment with rabeprazole costs 295,781 won. This result demonstrates that rabeprazole will cost 46,241 won more than omeprazole for annual GERD treatment and it is consistent with the results of this study. As a result, omeprazole emerges as a preferred treatment option for GERD.

\section{Discussion}

Long-term management of GERD with or without esophagitis has become important since reflux symptoms have an adverse impact on health-related QOL. Several studies have already demonstrated that full dose PPI is effective in the maintenance treatment of GERD. ${ }^{4,24}$ However, maintenance therapy using half dose PPI has not been fully evaluated, and furthermore, comparative studies on the therapeutic and cost effectiveness of half dose PPIs are relatively rare.

The present study has demonstrated that omeprazole $10 \mathrm{mg}$ once daily and rabeprazole $10 \mathrm{mg}$ once daily had similar efficacy and safety, but omeprazole $10 \mathrm{mg}$ had higher cost effectiveness than rabeprazole $10 \mathrm{mg}$ in preventing the relapse of erosive esophagitis and reflux symptoms during 6 months of treatment.
Table 4. Proportion of All Relevant Variables Used in the Decision Trees

\begin{tabular}{ll}
\hline \multicolumn{1}{c}{ Variables } & \multicolumn{1}{c}{ Proportion } \\
\hline Success of symptom control & $0.965(96.5 \%)$ \\
Failure of symptom control or relapse & $0.035(3.5 \%)$ \\
Continuous maintenance with full dose of PPI & $0.540(54.4 \%)$ \\
Continuous maintenance with half dose of PPI & $0.120(11.9 \%)$ \\
On demand therapy (with full or half dose PPI) & $0.290(28.7 \%)$ \\
Surgery & $0.050(5.0 \%)$ \\
\hline
\end{tabular}

PPI, proton pump inhibitor.

This result is not consistent with the findings of other studies. Previous studies have suggested that Rabeprazole $10 \mathrm{mg}$ once a day was equivalent to omeprazole $20 \mathrm{mg}$ once a day in preventing recurrence of erosive GERD, ${ }^{15,25}$ and rabeprazole $10 \mathrm{mg}$ provides more rapid acid inhibition compared with omeprazole 10 mg. ${ }^{26}$ Although successful acid suppression affects both the speed and degree of symptom relief and mucosal healing ${ }^{27,28}$ rabeprazole has a greater potency than omeprazole when compared on a milligram basis. ${ }^{29}$ However omeprazole $20 \mathrm{mg}$ is equivalent to rabeprazole $20 \mathrm{mg}$ in healing reflux esophagitis and in the maintenance therapy of reflux esophagitis, ${ }^{30}$ but there has been no direct comparison of the effectiveness of omeprazole $10 \mathrm{mg}$ and rabeprazole $10 \mathrm{mg}$ in the maintenance of erosive esophagitis up until this current study. The findings of the present study suggest that omeprazole $10 \mathrm{mg}$ once daily is at least as effective as rabeprazole $10 \mathrm{mg}$ in long-term maintenance therapy in LA grade A or B erosive esophagitis.

Another aim of this study was to assess the difference in total cost of maintenance treatments between omeprazole $10 \mathrm{mg}$ and rabeprazole $10 \mathrm{mg}$. Because using a PPI on demand and less often than daily is not as effective as continuous therapy for maintaining healing and symptom resolution, ${ }^{31}$ most patients with GERD need long-term continuous management and this can cause a significant economic burden. In the economic evaluation, we need to take into account that the costs for management of GERD are dependent on various practice patterns or treatment pathways in different countries and health care systems. In Korea, outpatient costs and drug dispensing costs are generally very low. This means that the main element of expense in management of GERD is cost of the medicine. In fact, in this study, PPI medicine cost accounted for $46 \%$ of the total cost and the difference of cost between the 2 drugs (the price of one omeprazole $10 \mathrm{mg}$ tablet is 472 won and the cost of one rabeprazole tablet is 724 won) can explain the difference in total costs in the management of 
GERD between the 2 groups. To conclude, omeprazole was the less costly option for the maintenance treatment of GERD compared with rabeprazole.

Symptomatic and endoscopic remission rates at 6 months (96.4\% for the omeprazole group and $93.3 \%$ for the rabeprazole group) of this study are relatively high compared with the rates observed in studies of esomeprazole $20 \mathrm{mg}(83 \%)^{32}$ and lansoprazole $15 \mathrm{mg}(74 \%) .{ }^{33} \mathrm{~A}$ possible explanation for this difference is that patients with LA grades C and D were excluded from this study. This may have increased the endoscopic remission rate at the end of 6 months. However, exclusion of patients with severe esophagitis might not have effect on symptom severity of GERD patients, since symptom severity is a poor predictor for the grade of esophagitis. ${ }^{34,35}$ A second possibility is that we analyzed symptomatic and endoscopic remission rates separately as a primary and second end point. Actually, if we change the definition of the primary end point as the proportion of patients in endoscopic plus symptomatic remission, the response rate of the omeprazole group is decreased to $91.6 \%$ and the response rate of the rabeprazole group is decreased to $90.2 \%$.

One possible limitation of our study was that the Helicobacter pylori test was not used in our study. Several reports have suggested that $H$. pylori positive patients were less likely to have GERD, and when present, the severity of esophagitis was decreased compared to those who were $H$. pylori negative. ${ }^{36,37}$ However, although admitting that a strong negative association exists between reflux esophagitis and H. pylori, GERD symptoms had no association with $H$. pylori status at baseline and follow-up after H. pylori eradication. ${ }^{38,39}$ Therefore, H. pylori infection itself might not have a significant effect on the result of this study.

It is interesting that although a high correlation between the absence of symptoms and maintenance of the healing of EE was found in a study of maintenance treatment with once daily esomeprazole for 6 months, ${ }^{8}$ there was no concurrence between the absence of reflux symptoms and maintenance of healing during maintenance therapy in this study. This finding was not in line with the report that the control of symptoms was a reliable indicator for maintained healing of esophagitis. ${ }^{24}$ However, mucosal erythema at endoscopy correlates poorly with reflux symptoms, ${ }^{40}$ and also the severity of GERD symptoms does not predict disease severity in patients with erosive esophagitis. ${ }^{41}$ Therefore, symptom relief alone may not be the basis for the resolution of erosive esophagitis.

In conclusion, treatment with omeprazole $10 \mathrm{mg}$ once daily in patients with Grade A or B erosive esophagitis is as effective as rabeprazole $10 \mathrm{mg}$ once daily in relieving symptoms, and well tolerated, and is superior to rabeprazole $10 \mathrm{mg}$ once daily in terms of cost effectiveness.

\section{References}

1. Yang SY, Lee OY, Bak YT, et al. Prevalence of gastroesophageal reflux disease symptoms and uninvestigated dyspepsia in Korea: a population-based study. Dig Dis Sci 2008;53:188-193.

2. Cho YS, Choi MG, Jeong JJ, et al. Prevalence and clinical spectrum of gastroesophageal reflux: a population-based study in Asan-si, Korea. Am J Gastroenterol 2005;100:747-753.

3. Vakil N, Fennerty MB. Direct comparative trials of the efficacy of proton pump inhibitors in the management of gastro-oesophageal reflux disease and peptic ulcer disease. Aliment Pharmacol Ther 2003; 18:559-568.

4. Moayyedi P, Talley NJ. Gastro-oesophageal reflux disease. Lancet 2006;367:2086-2100.

5. Bytzer P, Blum A, De Herdt D, Dubois D, Trial I. Six-month trial of on-demand rabeprazole $10 \mathrm{mg}$ maintains symptom relief in patients with non-erosive reflux disease. Aliment Pharmacol Ther 2004; 20:181-188.

6. Kaspari S, Kupcinskas L, Heinze H, Berghöfer P. Pantoprazole 20 $\mathrm{mg}$ on demand is effective in the long-term management of patients with mild gastro-oesophageal reflux disease. Eur J Gastroenterol Hepatol 2005;17:935-941.

7. Scholten T, Dekkers CP, Schütze K, Körner T, Bohuschke M, Gatz G. On-demand therapy with pantoprazole $20 \mathrm{mg}$ as effective long-term management of reflux disease in patients with mild GERD: the ORION trial. Digestion 2005;72:76-85.

8. Lee JH, Cho YK, Jeon SW, et al. [Guidelines for the treatment of gastroesophageal reflux disease.] Korean J Gastroenterol 2011;57: 57-66. [Korean]

9. Vakil NB, Shaker R, Johnson DA, et al. The new proton pump inhibitor esomeprazole is effective as a maintenance therapy in GERD patients with healed erosive oesophagitis: a 6-month, randomized, double-blind, placebo-controlled study of efficacy and safety. Aliment Pharmacol Ther 2001;15:927-935.

10. Collen MJ, Abdulian JD, Chen YK. Gastroesophageal reflux disease in the elderly: more severe disease that requires aggressive therapy. Am J Gastroenterol 1995;90:1053-1057.

11. Ouatu-Lascar R, Fitzgerald RC, Triadafilopoulos G. Differentiation and proliferation in Barrett's esophagus and the effects of acid suppression. Gastroenterology 1999;117:327-335.

12. Dent J. Australian clinical trials of omeprazole in the management of reflux oesophagitis. Digestion 1990;47(suppl 1):69-71.

13. Dent J, Yeomans ND, Mackinnon M, et al. Omeprazole v ranitidine for prevention of relapse in reflux oesophagitis. A controlled double blind trial of their efficacy and safety. Gut 1994;35:590-598.

14. Dekkers CP, Beker JA, Thjodleifsson B, Gabryelewicz A, Bell NE, Humphries TJ. Double-blind comparison [correction of Doubleblind, placebo-controlled comparison] of rabeprazole $20 \mathrm{mg}$ vs. omeprazole $20 \mathrm{mg}$ in the treatment of erosive or ulcerative gastro-oeso- 
phageal reflux disease. The European Rabeprazole Study Group. Aliment Pharmacol Ther 1999;13:49-57.

15. Thjodleifsson B, Rindi G, Fiocca R, et al. A randomized, double-blind trial of the efficacy and safety of 10 or $20 \mathrm{mg}$ rabeprazole compared with $20 \mathrm{mg}$ omeprazole in the maintenance of gastro-oesophageal reflux disease over 5 years. Aliment Pharmacol Ther 2003;17:343-351.

16. Carling L, Axelsson CK, Forssell H, et al. Lansoprazole and omeprazole in the prevention of relapse of reflux oesophagitis: a longterm comparative study. Aliment Pharmacol Ther 1998;12:985-990.

17. Mössner J, Hölscher AH, Herz R, Schneider A. A double-blind study of pantoprazole and omeprazole in the treatment of reflux oesophagitis: a multicentre trial. Aliment Pharmacol Ther 1995;9:321326.

18. Bardhan KD, Cherian P, Vaishnavi A, et al. Erosive oesophagitis: outcome of repeated long term maintenance treatment with low dose omeprazole $10 \mathrm{mg}$ or placebo. Gut 1998;43:458-464.

19. Bate CM, Booth SN, Crowe JP, et al. Omeprazole $10 \mathrm{mg}$ or $20 \mathrm{mg}$ once daily in the prevention of recurrence of reflux oesophagitis. Solo Investigator Group. Gut 1995;36:492-498.

20. Seong SS, Choi CB, Sung YK, et al. [Health-related quality of life using EQ-5D in Koreans.] J Korean Rheum Assoc 2004;11:254262. [Korean]

21. Chassany O, Holtmann G, Malagelada J, Gebauer U, Doerfler H, Devault K. Systematic review: health-related quality of life (HRQOL) questionnaires in gastro-oesophageal reflux disease. Aliment Pharmacol Ther 2008;27:1053-1070.

22. Hughes DA, Bodger K, Bytzer P, de Herdt D, Dubois D. Economic analysis of on-demand maintenance therapy with proton pump inhibitors in patients with non-erosive reflux disease. Pharmacoeconomics 2005;23:1031-1041.

23. Jeong YJ, Lee $\mathrm{DH}$, Choi $\mathrm{TH}$, et al. [Clinical analysis of recurrence rate and symptom improvement in gastro-esophageal reflux disease patients.] Korean J Gastroenterol 2010;55:100-108. [Korean]

24. Dent J, Brun J, Fendrick AM, et al. An evidence-based appraisal of reflux disease management - the Genval Workshop Report. Gut 1998;44(suppl 2):S1-S16.

25. Thjodleifsson B, Beker JA, Dekkers C, Bjaaland T, Finnegan V, Humphries TJ. Rabeprazole versus omeprazole in preventing relapse of erosive or ulcerative gastroesophageal reflux disease: a double-blind, multicenter, European trial. The European Rabeprazole Study Group. Dig Dis Sci 2000;45:845-853.

26. Bruley des Varannes S, Gharib H, Bicheler V, et al. Effect of low-dose rabeprazole and omeprazole on gastric acidity: results of a double blind, randomized, placebo-controlled, three-way crossover study in healthy subjects. Aliment Pharmacol Ther 2004;20:899907.

27. Burget DW, Chiverton SG, Hunt RH. Is there an optimal degree of acid suppression for healing of duodenal ulcers? A model of the relationship between ulcer healing and acid suppression. Gastroenterol- ogy 1990;99:345-351.

28. Howden CW, Hunt RH. The relationship between suppression of acidity and gastric ulcer healing rates. Aliment Pharmacol Ther 1990;4:25-33.

29. Stedman CA, Barclay ML. Review article: comparison of the pharmacokinetics, acid suppression and efficacy of proton pump inhibitors. Aliment Pharmacol Ther 2000;14:963-978.

30. Caro JJ, Salas M, Ward A. Healing and relapse rates in gastroesophageal reflux disease treated with the newer proton-pump inhibitors lansoprazole, rabeprazole, and pantoprazole compared with omeprazole, ranitidine, and placebo: evidence from randomized clinical trials. Clin Ther 2001;23:998-1017.

31. Sjostedt S, Befrits R, Sylvan A, et al. Daily treatment with esomeprazole is superior to that taken on-demand for maintenance of healed erosive oesophagitis. Aliment Pharmacol Ther 2005;22:183-191.

32. Labenz J, Armstrong D, Lauritsen K, et al. Esomeprazole $20 \mathrm{mg}$ vs. pantoprazole $20 \mathrm{mg}$ for maintenance therapy of healed erosive oesophagitis: results from the EXPO study. Aliment Pharmacol Ther 2005;22:803-811.

33. Lauritsen K, Devière J, Bigard MA, et al. Esomeprazole $20 \mathrm{mg}$ and lansoprazole $15 \mathrm{mg}$ in maintaining healed reflux oesophagitis: Metropole study results. Aliment Pharmacol Ther 2003;17:333-341.

34. Avidan B, Sonnenberg A, Schnell T, Sontag S. Acid reflux is a poor predictor for severity of erosive reflux esophagitis. Dig Dis Sci 2002; 47:2565-2573.

35. Okamoto K, Iwakiri R, Mori M, et al. Clinical symptoms in endoscopic reflux esophagitis: evaluation in 8031 adult subjects. Dig Dis Sci 2003;48:2237-2241.

36. Chung SJ, Lim SH, Choi J, et al. Helicobacter pylori serology inversely correlated with the risk and severity of reflux esophagitis in Helicobacter pylori endemic area: a matched case-control study of 5,616 health check-up Koreans. J Neurogastroenterol Motil 2011; 17:267-273.

37. Koike T, Ohara S, Sekine H, et al. Helicobacter pylori infection prevents erosive reflux oesophagitis by decreasing gastric acid secretion. Gut 2001;49:330-334.

38. Nam SY, Choi IJ, Ryu KH, Kim BC, Kim CG, Nam BH. Effect of Helicobacter pylori infection and its eradication on reflux esophagitis and reflux symptoms. Am J Gastroenterol 2010;105:2153-2162.

39. Nordenstedt H, Nilsson M, Johnsen R, Lagergren J, Hveem K. Helicobacter pylori infection and gastroesophageal reflux in a population-based study (The HUNT Study). Helicobacter 2007;12: 16-22.

40. Johnsson F, Joelsson B, Gudmundsson K, Greiff L. Symptoms and endoscopic findings in the diagnosis of gastroesophageal reflux disease. Scand J Gastroenterol 1987;22:714-718.

41. Fennerty MB, Johnson DA. Heartburn severity does not predict disease severity in patients with erosive esophagitis. MedGenMed 2006; $8: 6$. 